\title{
GAIA Neonatal Case Definitions
}

National Cancer Institute

\section{Source}

National Cancer Institute. GAIA Neonatal Case Definitions. NCI Thesaurus. Code C126830.

A set of terms and defintions created by the Global Alignment of Immunization safety Assessment in pregnancy that are related to the neonatal effects of immunizations. 